\title{
Exportações e competitividade da carne de frango brasileira e paranaense no período de 1990 a 2005
}

\section{Exportations and competitiveness of poultry meat from Brazil and the state of Paraná, in the period between 1990 and 2005}

\author{
Luiz Gustavo Antonio de Souza'; Marcia Regina Gabardo da Camara²; \\ Vanderlei José Sereia ${ }^{3}$
}

\begin{abstract}
Resumo
O complexo de carnes é um dos principais componentes da pauta de exportação brasileira. As carnes de frangos apresentam grande participação nas exportações brasileiras, sendo que o Estado do Paraná é o maior estado produtor exportador do Brasil. O objetivo do trabalho é analisar o comportamento e a competitividade das exportações do complexo agroindustrial de carnes de frangos brasileiro e paranaense no período de 1990 a 2005 , bem como os fatores que determinam o desempenho das exportações brasileiras e sua interação com o comércio internacional. O modelo principal de análise utilizado é o "Constant-Market-Share", que realiza a decomposição as fontes de crescimento das exportações dos complexos agroindustriais em componentes denominados: "crescimento do mercado mundial", "composição da pauta de exportação", "destino das exportações" e "competitividade" e são capazes de expressar o comportamento e padrão das exportações no período de estudo. O método da taxa geométrica de crescimento, por meio do Método dos Mínimos Quadrados Ordinários, foi utilizado para analisar a evolução do complexo no período. A fim de alcançar os objetivos e verificar o padrão das exportações brasileiras e a competitividade do frango brasileiro, foram colhidos dados sobre exportações e importações mundiais de carne dos anos de 1990 a 2005, de forma que se identificasse o perfil dos grandes mercados consumidores e exportadores do complexo carnes. Os dados analisados permitiram concluir que os indicadores do Brasil e do Estado do Paraná evoluíram a altas taxas de crescimento geométricas de carne de frango. A partir da análise dos resultados do modelo CMS, percebe-se que o Brasil e o Paraná possuem elevada competitividade e alto market-share no segmento analisado. A crescente demanda por este tipo de carne permitirá que o Brasil se consolide internacionalmente nesse mercado, além de serem sugeridas políticas sanitárias e outras que possam reduzir as barreiras à entrada deste produto nos principais países importadores.
\end{abstract}

Palavras-Chave: Competitividade. Frangos. Carnes. Economia internacional.

\begin{abstract}
The meat complex is one of the main components of the Brazilian export agenda. Poultry meat plays an important role in Brazilian exportations, being the State of Paraná the leader in this sector. The purpose of this work is to analyze the behavior and competitiveness of exportations in the agroindustrial poultry meat complex in Brazil and in the State of Paraná, in the period between 1990 and 2005 , as well as the factors that determine the performance of Brazilian exportations and its interaction with the international trade. The Constant-Market-Share analysis was used, identifying the sources of agribusiness exportations growth complex, as follows: "worldwide market growth", "export agenda elaboration", "exportations destination" and "competitiveness", which are able to express the behavior

\footnotetext{
Economista, Doutorando em Economia Aplicada - ESALQ/USP - E-mail: lgasouza@esalq.usp.br

2 Professora do Departamento de Economia da UEL-E-mail: mgabardo@sercomtel.com.br

3 Professor do Departamento de Economia da UEL - E-mail: sereia@uel.br
} 
and pattern of exportations in the analyzed period. The geometrical growth rate method, by means of the Ordinary Least Square Method, was used to analyze the development of the complex in the period. In order to achieve the goals and verify the pattern of Brazilian exportations and the competitiveness of Brazilian poultry meat, data on worldwide exportations and importations of poultry meat in the period of 1990 to 2005 were gathered, so that it would be possible to identify the profile of the biggest consumer markets and the meat complex exporters. The analyzed data enabled us to conclude that the geometric growth rates of poultry meat increased in Brazil and in the State of Paraná, as well. The analysis of the CMS results shows that Brazil and the State of Paraná have high competitiveness and market-share in the analyzed segment. The increasing demand for this type of meat will enable Brazil to be consolidated internationally in this market, besides suggesting sanitary policies that might reduce barriers to the entrance of this product to the main import countries.

Key words: Competitiveness. Poultry meat. Meat. International economy.

\section{Introdução}

A competitividade internacional dos complexos agroindustriais tem alimentado debates e estudos nos países em desenvolvimento nos últimos vinte e cinco anos. Entre as especificidades do complexo de carnes, salienta-se o fato de que as carnes são importante fonte de proteínas, constituem um bem básico para as necessidades humanas, possuem elasticidade-renda positiva, mas inferior a um, uma vez que uma elevação percentual na renda não eleva mais que proporcionalmente o consumo (CARVALHO; BACCHI, 2007).

As carnes constituem produtos destinados à alimentação, e, assim, enfrentam os problemas sanitários, e podem causar danos à saúde humana. Esses danos influenciam a decisão dos agentes e alteram o fluxo de comércio internacional. Os problemas sanitários, juntamente com outras medidas tarifárias, são vistas como barreiras ao comércio.

A caracterização da oferta mostra que os produtores de carnes necessitam um período maior de maturação de suas commodities, e mesmo de seus investimentos, provocando impactos negativos em preços. Ocorre que há uma oferta perfeitamente inelástica no curto prazo, e, com isso, os produtores passam a ser os principais afetados e distribuem os ônus para os outros setores da economia.

O Brasil passou de quarto maior exportador de carne de frangos no período 1990-1991 para o maior do mundo, em valor, no período 2004-2005, para os principais cortes da carne. O complexo de carne de frangos tem crescido no Brasil a partir da década de 90, impulsionado pela abertura comercial que permitiu maior inserção no mercado internacional, bem como a criação de condições internas, como a produção verticalizada, junto a produtores que negociam contratos com a indústria de abate. Houve integração na divisão inter-regional do trabalho no Rio Grande do Sul, em Santa Catarina, no Paraná e em São Paulo. O crescimento da área plantada de soja e a instalação da indústria oleaginosa facilitaram a implantação concentrada da indústria avícola na Região Sul, sobretudo no Paraná.

Comparado aos outros complexos de carne exportados pelo Brasil, este apresentou o maior crescimento no período, com tendência crescente para os próximos períodos. Assim, o período entre 1990 e 2005 torna-se um lócus importante para a análise dos determinantes do crescimento das exportações, a qual se torna importante para futuras políticas setoriais.

Os estudos dos complexos agroindustriais colocam em discussão os fundamentos da competitividade internacional, em um contexto crescentemente globalizado, questionando se realmente os postulados das vantagens comparativas e da divisão internacional do trabalho são válidos, dadas às perdas inerentes do comércio internacional que não traduzem as expectativas dos agentes que dela participam.

A discussão da competitividade em termos internacionais, naatualidade, resgata as contribuições 
de Smith e Ricardo e são a base da discussão do comércio entre as nações. As trocas ocorrem quando uma nação é mais eficiente na produção de uma mercadoria e menos eficiente em uma segunda mercadoria, e as nações podem ganhar, se cada uma vier a especializar-se na produção da mercadoria de sua vantagem absoluta (CARVALHO; SILVA, 2004; KRUGMAN; OBSTFELD, 2004).

A importância que se releva aos complexos agroindustriais deve-se à sua participação crescente na formação do PIB das nações emergentes, das que são pautadas no conceito de agribusiness, e, assim, relacionadas ao comércio internacional e competitividade, traduzindo em ganhos no quantum exportado e market-share.

Adiscussão acerca dos complexos agroindustriais no Brasil surge a partir do processo de industrialização brasileira. Anteriormente, a economia, de base agropecuária, fornecia grande parte do produto diretamente aos canais de comercialização, mas depois surgiu um sistema integrado, em que a agricultura se torna parte funcional da indústria. Com isso, o enfoque mudou da agricultura para a indústria (MARAFON; MADANELO, 2004).

Há uma diversidade de enfoques associados ao conceito de complexos agroindustriais, e, nesse campo, cabe salientar os trabalhos seminais de Davis e Goldenberg, a partir da definição por Malassis de agribusiness e cadeias agroindustriais (com as filières) e o também de cadeias produtivas e complexos industriais (MARAFON;MADANELO, 2004;MARAFON, 2007; DANTAS, KERTSNETZKY; PROCHNIK, 2002). No Brasil, os estudos de complexos agroindustriais iniciam-se com as traduções teóricas das principais correntes de pesquisa e com aplicações macrosetoriais, abrangendo as diversas relações e a existência de grandes complexos. Entretanto, as discussões recentes enfocam um movimento de particularização das atividades, de modo que seja dado entender, de modo pormenorizado, as relações . Também se busca compreender como a competitividade pode ser determinada por suas características inerentes e influências setoriais.

Logo, a definição de complexo agroindustrial com setores particulares e enfoque na indústria como elemento integrador aproxima-se da realidade, e possibilita que as nações passem de um enfoque local para o global.

A competitividade deriva da produtividade empresas e está ligada à capacidade de o governo criar condições favoráveis para o aproveitamento dos recursos naturais e construídos, e pode ser aferida por indicadores nacionais/ internacionais. $\mathrm{O}$ aumento de competitividade de carnes brasileiras permite a conquista da fatia de mercado internacional adicionais. Segundo Coutinho e Ferraz (1994), os fatores que contribuem para a competitividade são fatores internos à empresa, estruturais (setoriais) e sistêmicos (estratégia e gestão; capacitação para inovação; capacitação produtiva e recursos humanos). A competitividade, vista como um desempenho, é expressa pela participação no mercado (market-share) alcançada por uma firma em um mercado em certo momento do tempo. A participação das exportações da firma ou conjunto de firmas (indústria ou nação) no comércio internacional total da mercadoria aparece como seu indicador mais imediato. A competitividade é uma variável "ex-post" que sintetiza os fatores preço e não-preço (qualidade de produtos e de fabricação, habilidade de servir ao mercado, capacidade de diferenciação de produtos) (FERRAZ; KUPFER; HAGUENAUER, 1995).

Adota-se o conceito de competitividade expost, associada ao desempenho, dada a natureza do método utilizado para avaliar o comportamento e a competitividade das exportações do complexo carnes de frango brasileiro, o modelo "ConstantMarket-Share” (CMS). O modelo é amplamente utilizado para analisar exportações entre períodos discretos, uma vez que permite identificar os principais determinantes do crescimento das exportações, como o crescimento do comércio 
mundial, do destino e da competitividade, e sua aplicação em complexos agroindustriais se ajusta bem ao modelo. Esta análise enfatiza o desempenho do mercado exportador em relação ao seu mercado importador.

Outra ferramenta de análise é a taxa de crescimento geométrica, pois esta, ao ponderar todos os dados utilizados e utilizar um ferramental econométrico, permite maior acurácia do indicador, ou seja, dadas certas condições, permite criar uma tendência, e esta representa o crescimento das exportações ao longo do tempo. Como outros indicadores apenas utilizam valores finais e iniciais, ou médias simples, esta apresenta um diferencial, representado pelo seu poder de explicação, e podem ser testados estatisticamente.

$\mathrm{O}$ artigo se estrutura em cinco seções, inclusa a introdução. Na segundo seção é apresentada uma análise conjuntural para o setor, com ênfase nas exportações e importações mundiais do complexo. $\mathrm{Na}$ terceira seção, são apresentados os materiais e métodos utilizados. Na quarta seção, expõe-se os principais resultados e discussões e a última seção, a conclusão do artigo.

\section{Análise conjuntural}

A indústria de frangos no Brasil, enquanto processamento industrial, surge no final dos anos 60 , transformando-se em um dos principais segmentos da indústria de carnes, em função da instalação de grandes empresas oligopolizadas e integradoras, a partir de fins dos anos 70. Aimportação da tecnologia de processo permite a integração vertical, a produção das atividades complementares ao abate e o esquema contratual de criação das aves junto aos produtores avícolas. A incorporação da genética importada ao processo produtivo e o aumento do preço da carne bovina levaram ao aumento da produção e consumo da carne de frango.

A indústria brasileira de carne de frango cresceu e houve a integração na divisão inter-regional do trabalho no Rio Grande do Sul, em Santa Catarina, no Paraná e em São Paulo. No Paraná, as empresas se instalaram nos anos 70 e atuavam quase exclusivamente no segmento carne de frango. O crescimento da área plantada de soja e a instalação da indústria oleaginosa facilitaram a implantação concentrada da indústria avícola na Região Sul e no Paraná, em particular.

Os estados do Sul são grandes produtores de milho, e entre eles salienta-se o Paraná. Para Rizzi (1999), as condições facilitadoras se aliaram às políticas públicas de incentivos à implantação de indústrias e induziram a combinação de diversas atividades complementares da cadeia produtiva do complexo carne de aves. A indústria avícola cresceu vinculada à expansão das culturas de milho e soja, e permite a transformação de proteína vegetal em proteína animal.

Houve mudanças qualitativas no processo produtivo da indústria avícola ao longo da década de 80, como a incorporação de tecnologias ao nível do abate de aves, a crescente automatização, o uso de novos tipos de máquinas e equipamentos para o processamento de produtos recortados e industrializados. Associado à inovação,houve o lançamento de novos cortes e embutidos, que buscavam atender ao mercado segmentado.

Segundo Martinelli e Souza (2005, p.1)

A Avicultura Industrial Brasileira notabilizou-se por profundas mudanças nos últimos anos. O segmento evoluiu através da absorção de contribuições advindas da biotecnologia e das tecnologias complementares da microeletrônica e da automação. O bom desempenho nos mercados (interno e externo) pôde ser alcançado por meio de duas estratégias: a redução do custo das matérias-primas e o atendimento das necessidades específicas dos consumidores (em ambos os mercados).

O grau de articulação entre os diferentes elos do complexo agroindustrial avícola de corte é um dos mais elevados no agronegócio nacional. Sob a coordenação das agroindústrias de abate e processamento, sobretudo através dos contratos estabelecidos com a 
base de produção rural para terminação de frangos e de joint ventures estabelecidas com grandes empresas multinacionais de desenvolvimento genético, este circuito de produção agroindustrial atingiu elevados patamares de desenvolvimento ao longo dos últimos 30 anos, permitindo que o produto frango se incorporasse ao hábito alimentar de grande parcela da população.
Entre os principais importadores de carne de frango, salienta-se o Reino Unido, com cerca de 1,3 bilhões de dólares. Entre os continentes, o maior importador é a Ásia, onde a China e o Japão situamse entre as oito maiores nações.

Tabela 1. Principais países importadores de carne de frangos em 2005 e sua posição média relativa ao período 1990 e 2005.

\begin{tabular}{lcccc}
\hline País & $\begin{array}{c}\text { Posição em } \\
2005\end{array}$ & $\begin{array}{c}\text { Posição na média } \\
(1990-2005)\end{array}$ & $\begin{array}{c}\text { Valor importação em } \\
\text { US\$ } 1.000\end{array}$ & $\begin{array}{c}\text { Valor importado médio } \\
(1990-2005) \\
\text { em US\$1.000 }\end{array}$ \\
\hline Reino Unido & $1^{\circ}$ & $3^{\circ}$ & $1.291 .484,09$ & $578.725,61$ \\
China & $2^{\circ}$ & $2^{\circ}$ & $914.327,46$ & $679.636,04$ \\
Japão & $3^{\circ}$ & $1^{\circ}$ & $885.612,70$ & $820.770,75$ \\
Rússia & $4^{\circ}$ & $6^{\circ}$ & $816.412,74$ & $218.286,03$ \\
Arábia Saudita & $5^{\circ}$ & $9^{\circ}$ & $639.709,32$ & $146.305,52$ \\
Alemanha & $6^{\circ}$ & $4^{\circ}$ & $616.743,81$ & $492.344,78$ \\
Hong Kong & $7^{\circ}$ & $5^{\circ}$ & $500.519,88$ & $491.321,66$ \\
Holanda & $8^{\circ}$ & $7^{\circ}$ & $445.572,31$ & $192.295,51$ \\
\hline
\end{tabular}

Fonte: Elaboração do autor a partir de dados da Food and Agriculture Organization - FAO (2006).

Obs.: Valores corrigidos pelo índice de commodities.

O complexo carne de frangos possui economias de escala na sua produção, com possibilidades de economias locacionais oriundas da integração vertical das atividades, e os produtores fornecem os frangos ao abatedouro com as especificações necessárias firmadas em contratos.

Assim, os países que possuem maior ociosidade nas propriedades e disponibilidade de produtores rurais, conseguem ter, como alternativa, uma produção rentável e com custos dissolvidos pela indústria integradora.
Entre os principais exportadores de carne de frangos e miúdos encontra-se o Brasil com o primeiro lugar no ranking, e o segundo na média no período (ver Tabela 2). Os Estados Unidos aparecem em segundo lugar, porém em primeiro na média calculada, com um valor de US\$1.350.597,34 (em US\$ 1.000). A Holanda manteve sua posição média no período atual, mesma posição nas exportações de carne de bovinos apresentada nas tabelas anteriores. 
Tabela 2. Principais países exportadores de carne de frangos em 2005 e sua posição média relativa ao período 1990 e 2005 .

\begin{tabular}{lcccc}
\hline País & $\begin{array}{c}\text { Posição em } \\
2005\end{array}$ & $\begin{array}{c}\text { Posição na média } \\
(1990-2005)\end{array}$ & $\begin{array}{c}\text { Valor exportação em } \\
\text { US\$ } 1.000\end{array}$ & $\begin{array}{c}\text { Valor exportado médio } \\
(1990-2005) \\
\text { em US\$ } 1.000\end{array}$ \\
\hline Brasil & $1^{\circ}$ & $2^{\circ}$ & $3.490 .092,28$ & $969.580,38$ \\
Estados Unidos & $2^{\circ}$ & $1^{\circ}$ & $2.216 .865,95$ & $1.350 .597,34$ \\
Holanda & $3^{\circ}$ & $3^{\circ}$ & $1.221 .907,07$ & $734.249,45$ \\
França & $4^{\circ}$ & $4^{\circ}$ & $721.393,64$ & $620.542,22$ \\
Alemanha & $5^{\circ}$ & $8^{\circ}$ & $360.053,76$ & $149.312,26$ \\
China & $6^{\circ}$ & $5^{\circ}$ & $326.192,38$ & $609.984,81$ \\
Reino Unido & $7^{\circ}$ & $9^{\circ}$ & $280.493,38$ & $133.389,76$ \\
Polônia & $8^{\circ}$ & $13^{\circ}$ & $243.397,27$ & $43.364,29$ \\
\hline
\end{tabular}

Fonte: Elaboração do autor a partir de dados da FAO (2006).

Obs.:Valores corrigidos pelo índice de commodities.

A crescente demanda mundial por carne de frangos é fruto, em parte, da mudança do gosto do consumidor mundial que procedeu à substituição da proteína bovina, dados problemas derivados da disseminação da doença da encefalopatia espongiforme bovina (mal da vaca louca), e da febre aftosa em vários rebanhos ao redor do globo. Porém, o complexo de carnes de frango, juntamente com o complexo de outras aves, como perus e patos enfrentam problemas. Segundo a Folha Online (VEJA..., 2006), a Organização Mundial da Saúde (OMS) já contabiliza 95 mortes desde o surgimento do vírus da gripe aviária entre 2003 e 2006. Por outro lado, já é comprovada a sua transmissão para outras espécies de animais inclusive humanos, dada a presença de mutações viróticas similares ás verificadas nos vírus da gripe comum. Os principais países asiáticos estão sofrendo com os casos de gripe aviária; as aves migratórias são o principal problema, porque permitem a disseminação da doença em escala internacional.

Essa doença letal tanto para as aves atingidas quanto para os seres humanos fará com que a demanda mundial desse produto possa cair, ou mesmo elevar nos países que estão em quarentena. Os países que têm possibilidade de atender esse mercado poderão ampliar a parcela exportada nos próximos anos. As barreiras sanitárias que a carne brasileira de aves enfrenta no exterior estão associadas ao vírus da Influenza Aviária: Doença de Newcastle; presença de antibióticos (Nicarbazina e Nitrofurano); presença de promotores de crescimento (Avilamicina e Flavomicina). No que tange às certificações internacionais voltadas para a qualidade alimentar, verifica-se: a ausência de indicadores de Rastreabilidade; a necessidade de adotar e disseminar o programa de boas práticas reconhecidas pelo - GMP (Good Manufacturing Practices); a necessidade de adotar o programa HACCP (Hazard Analysis Critical Control Points); e a reclassificação tarifária do frango salgado $(1,2 \%$ para 1,9\%) (MARTINELLI; SOUZA, 2005).

O programa GMP é adotado pela Organização Mundial de Saúde e o FDA (Food and Drugs Administration) como critério mínimo recomendado para fabricação dos produtos sob condições sanitárias adequadas e como rotina de inspeção. Contempla aspectos higiênicos e sanitários, incluindo a eliminação da contaminação microbiológica, física e química. O sistema HACCP busca estabelecer o controle em todo o processo produtivo, considerando a matéria-prima, o processamento e ambiente até os operadores envolvidos na produção. Pode ser utilizado para controle de qualquer área sujeita a 
uma condição de risco na produção de alimentos. Os riscos de contaminação englobam desde microorganismos patogênicos, remédios ingeridos pelos animais, lubrificantes utilizados nas máquinas e equipamentos dos abatedouros até as atividades de manejo, criação e engorda realizada nas granjas. (MARTINELLI; SOUZA, 2005).

O Brasil é um país cujas bases produtivas são agrícolas voltadas à exportação, dada sua vantagem comparativa na produção de commodities e que prossegue nos moldes da divisão internacional do trabalho (DIT). Uma característica diferenciada da produção de carnes no Brasil é sua extensão territorial - grande parte do complexo se caracteriza por ser de pasto e de forma extensiva. Há ganhos de competitividade com carnes, com menores teores de lipídios deixando-a mais saudável e com maior valor nutritivo, sendo alimentados por pasto ao invés de ração de origem animal. Essa pequena diferenciação pode influenciar na competitividade de um país quando há oscilações no ambiente institucional.

A Tabela 3 mostra a evolução dos principais complexos de carnes. Pode-se salientar que, dentre os rebanhos dos complexos de carnes tradicionais, o de galinhas, galos, frangos e pintos (agrega-se ao complexo aves) corresponde ao maior rebanho brasileiro, em mil cabeças.

Tabela 3. Evolução do rebanho brasileiro por tipo de animais entre 1990 e 2005 (em mil cabeças).

\begin{tabular}{|c|c|c|c|c|c|c|c|c|c|c|c|c|}
\hline Ano & Bovinos & Bubalinos & Suínos & Galinhas & $\begin{array}{l}\text { Galos, } \\
\text { Frangos e } \\
\text { Pintos }\end{array}$ & Asininos & Muares & Eqüinos & Caprinos & Ovinos & Coelhos & Codornas \\
\hline 1990 & 147.102 .314 & 1.397 .097 & 33.623 .186 & 174.508 .355 & 371.727 .150 & 1.342 .199 & 2.032 .924 & 6.121 .515 & 11.894 .587 & 20.014 .505 & 696.894 & 2.464 .016 \\
\hline 1991 & 152.135 .505 & 1.432 .112 & 34.290 .275 & 200.544 .113 & 393.848 .481 & 1.364 .199 & 2.035 .039 & 6.232 .607 & 12.172 .146 & 20.127 .945 & 649.226 & 2.542 .093 \\
\hline 1992 & 154.229 .303 & 1.423 .348 & 34.532 .168 & 204.160 .371 & 435.464 .988 & 1.381 .401 & 2.046 .367 & 6.329 .213 & 12.159 .564 & 19.955 .874 & 593.298 & 2.488 .172 \\
\hline 1993 & 155.134 .073 & 1.498 .890 & 34.184 .187 & 201.784 .802 & 452.382 .206 & 1.302 .374 & 1.992 .934 & 6.314 .130 & 10.618 .531 & 18.008 .283 & 564.766 & 2.417 .950 \\
\hline 1994 & 158.243 .229 & 1.571 .349 & 35.141 .839 & 207.539 .242 & 473.548 .803 & 1.312 .698 & 1.987 .219 & 6.355 .725 & 10.879 .286 & 18.436 .098 & 542.296 & 2.424 .280 \\
\hline 1995 & 161.227 .938 & 1.641 .950 & 36.062 .103 & 188.367 .357 & 541.163 .942 & 1.344 .155 & 1.990 .108 & 6.394 .145 & 11.271 .653 & 18.336 .432 & 499.854 & 2.939 .376 \\
\hline 1996 & 158.288 .540 & 1.046 .106 & 29.202 .182 & 178.527 .564 & 549.558 .943 & 1.231 .893 & 1.285 .628 & 5.705 .096 & 7.436 .454 & 14.725 .503 & 318.952 & 4.219 .887 \\
\hline 1997 & 161.416 .157 & 977.767 & 29.637 .109 & 179.628 .673 & 580.992 .997 & 1.248 .507 & 1.294 .507 & 4.831 .533 & 7.968 .169 & 14.533 .716 & 330.449 & 4.303 .237 \\
\hline 1998 & 163.154 .357 & 1.017 .246 & 30.006 .946 & 175.851 .681 & 589.370 .346 & 1.232 .750 & 1.292 .412 & 5.866 .780 & 8.164 .153 & 14.268 .387 & 345.479 & 4.707 .143 \\
\hline 1999 & 164.621 .038 & 1.068 .059 & 30.838 .616 & 180.194 .312 & 624.381 .496 & 1.236 .401 & 1.335 .771 & 5.831 .341 & 8.622 .935 & 14.399 .960 & 376.987 & 4.837 .506 \\
\hline 2000 & 169.875 .524 & 1.102 .551 & 31.562 .111 & 183.494 .626 & 659.245 .547 & 1.242 .177 & 1.347 .855 & 5.831 .817 & 9.346 .813 & 14.784 .958 & 375.573 & 5.775 .181 \\
\hline 2001 & 176.388 .726 & 1.118 .823 & 32.605 .112 & 190.233 .644 & 692.654 .775 & 1.239 .025 & 1.345 .656 & 5.801 .055 & 9.537 .439 & 14.638 .925 & 348.779 & 6.045 .342 \\
\hline 2002 & 185.347 .198 & 1.114 .720 & 32.013 .227 & 180.296 .601 & 727.725 .761 & 1.217 .045 & 1.338 .921 & 5.790 .008 & 9.428 .622 & 14.287 .157 & 337.135 & 5.572 .068 \\
\hline 2003 & 195.551 .576 & 1.148 .808 & 32.304 .905 & 183.799 .736 & 737.523 .096 & 1.208 .660 & 1.345 .389 & 5.828 .376 & 9.581 .653 & 14.556 .484 & 335.555 & 5.980 .474 \\
\hline 2004 & 204.512 .737 & 1.133 .622 & 33.085 .299 & 184.786 .319 & 759.512 .029 & 1.196 .324 & 1.358 .419 & 5.787 .250 & 10.046 .888 & 15.057 .838 & 324.582 & 6.243 .202 \\
\hline 2005 & 207.156 .696 & 1.173 .629 & 34.063 .934 & 186.573 .334 & 812.467 .900 & 1.191 .533 & 1.388 .665 & 5.787 .249 & 10.306 .722 & 15.588 .041 & 303.640 & 6.837 .767 \\
\hline
\end{tabular}

Fonte: Dados IBGE, 2007, online. Elaboração dos autores.

A Tabela 4 mostra como evoluiu o rebanho paranaense no período em análise. Nela se verifica que, em 2005, o maior rebanho era o referente ao de aves, especialmente o de frangos de corte totalizando 151.814 .509 cabeças. Comparativo ao Brasil, o estado paranaense representava $18,68 \%$ do rebanho brasileiro. 
Tabela 4. Evolução do rebanho paranaense por tipo de animais entre 1990 e 2005 (em cabeças)

\begin{tabular}{ccccccccccccc}
\hline Ano & Bovinos & Bubalinos & Suínos & Galinhas & $\begin{array}{c}\text { Galos, } \\
\text { Frangose } \\
\text { Pintos }\end{array}$ & Asininos & Muares & Equinos & Caprinos & Ovinos & Coelhos & Codornas \\
\hline 1990 & 8.616 .783 & 83.527 & 3.561 .765 & 20.281 .708 & 52.686 .248 & 1.942 & 118.043 & 448.567 & 265.952 & 385.316 & 133.921 & 74.146 \\
1991 & 8.541 .933 & 91.684 & 3.698 .205 & 21.242 .219 & 55.783 .573 & 1.924 & 115.743 & 449.316 & 272.906 & 417.589 & 104.067 & 120.956 \\
1992 & 8.498 .877 & 91.286 & 3.738 .365 & 22.791 .365 & 61.587 .794 & 1.926 & 114.019 & 442.249 & 270.274 & 462.099 & 77.664 & 130.561 \\
1993 & 8.606 .629 & 87.807 & 3.780 .172 & 20.466 .872 & 64.756 .291 & 1.867 & 111.985 & 439.980 & 254.033 & 526.930 & 62.751 & 109.037 \\
1994 & 8.911 .986 & 89.160 & 3.762 .598 & 20.640 .899 & 71.790 .858 & 1.767 & 109.580 & 438.939 & 228.423 & 597.616 & 51.835 & 116.728 \\
1995 & 9.389 .200 & 94.069 & 3.929 .636 & 21.872 .957 & 89.020 .286 & 2.126 & 105.298 & 430.214 & 206.456 & 598.731 & 45.058 & 158.820 \\
1996 & 9.879 .889 & 78.907 & 4.065 .636 & 17.397 .505 & 79.787 .567 & 3.100 & 58.212 & 454.725 & 85.178 & 545.823 & 26.815 & 258.481 \\
1997 & 9.896 .554 & 59.855 & 4.121 .617 & 17.701 .601 & 88.925 .275 & 3.673 & 60.481 & 480.274 & 80.561 & 558.507 & 24.665 & 278.304 \\
1998 & 9.766 .594 & 61.325 & 4.187 .103 & 18.343 .691 & 92.879 .761 & 3.605 & 61.523 & 495.568 & 81.377 & 573.686 & 26.146 & 412.855 \\
1999 & 9.472 .808 & 65.770 & 4.217 .063 & 18.902 .041 & 104.895 .969 & 3.437 & 60.094 & 482.300 & 78.902 & 570.382 & 28.602 & 520.958 \\
2000 & 9.645 .866 & 65.064 & 4.224 .838 & 19.184 .323 & 123.293 .408 & 3.471 & 59.425 & 479.928 & 78.870 & 548.998 & 28.397 & 518.306 \\
2001 & 9.816 .547 & 49.460 & 4.385 .914 & 20.170 .139 & 131.889 .638 & 3.319 & 57.496 & 470.302 & 80.880 & 543.954 & 28.190 & 450.209 \\
2002 & 10.048 .172 & 52.823 & 4.258 .075 & 19.695 .649 & 142.763 .759 & 3.251 & 56.617 & 462.646 & 85.346 & 548.634 & 30.606 & 299.204 \\
2003 & 10.258 .535 & 45.101 & 4.364 .371 & 20.433 .177 & 121.298 .743 & 3.148 & 56.461 & 459.294 & 92.390 & 507.850 & 32.237 & 517.941 \\
2004 & 10.278 .148 & 44.045 & 4.588 .053 & 19.355 .358 & 139.571 .936 & 3.047 & 55.355 & 434.381 & 96.731 & 488.142 & 28.386 & 477.552 \\
2005 & 10.153 .375 & 40.187 & 4.547 .895 & 19.839 .533 & 151.814 .509 & 3.025 & 54.038 & 426.004 & 114.796 & 511.801 & 34.640 & 494.506 \\
\hline
\end{tabular}

Fonte: Dados IBGE, 2007, online. Elaboração dos autores.

\section{Materiais e métodos}

A pesquisa utilizou de dois métodos para a análise tanto da evolução, quanto da competitividade do complexo-carne. O primeiro método analisa a evolução do complexo por meio das estimativas de crescimento geométrico, obedecendo às características do modelo de mínimos quadrados ordinários. O segundo método disucte a competitividade do complexo através da metodologia do "Constant-Market-Share" (CMS), uma análise estática que permite obter os ganhos oriundos do comércio internacional nos períodos analisados, pela decomposição em quatro fatores de crescimento. Para as análises, foram coletados dados da "FoodandAgriculture Organization"(FAO,2007), referentes às exportações e importações mundiais de carnes; do Ministério do Desenvolvimento, Indústria e Comércio Exterior (MDIC,2007) Secretaria de Comércio Exterior(SECEX), por meio do sistema ALICEWEB, que possui dados referentes às exportações brasileiras por país de destino, além de dados do Instituto Brasileiro de Geografia e Estatísticas (IBGE).
Método de taxa de crescimento geométrica através dos mínimos quadrados ordinários (MQO)

Muitos economistas procuram analisar a taxa de crescimento de certas variáveis, como as exportações, importações, produto, para assim analisarem sua evolução em determinado período. Entretanto, as técnicas de obtenção de taxa de crescimento podem não refletir a real magnitude, uma vez que os dados utilizados são referentes ao período inicial e final, e deixam de lado os dados intermediários, subestimando ou superestimando os dados. Assim, há a necessidade de uma técnica que pondere cada elemento da série temporal analisada. Como descreve Gujarati (2006), a função de crescimento de certa variável Y pode ser descrita por: $Y_{t}=Y_{0}(1+r)^{t}$, onde "r" é a taxa de crescimento composta ou geométrica ao longo do tempo " $t$ " de Y. Assim, se essa função obedecer às hipóteses da teoria dos Mínimos Quadrados Ordinários (MQO), essa função possuirá uma regressão linear, e é possível determinar a taxa de crescimento geométrica, pela ponderação de cada elemento da série. 
Dessa forma, assumindo as dezhipóteses de MQO e que $\hat{\beta}_{2}$ é o melhor estimador não tendencioso de $\hat{\beta}_{2}$, ou seja, $E\left(\hat{\beta}_{2}\right)=\beta_{2}$, é possível realizar a regressão simples da função com duas variáveis. No caso da taxa de crescimento geométrica, é preciso que transformar a função original para que esta seja admitida nas dez hipóteses. Assim, aplicando o ln em ambos os lados da função $Y_{t}=Y_{0}(1+r)^{t}$ temos: $\ln Y_{i}=\ln Y_{0}+t \ln (1+r)$, considerando assim que: $\quad \beta_{1}=\ln Y_{0}$ e $\beta_{2}=\ln (1+r) \quad$ e $\beta_{2}=\ln (1+r)$, reescrevendo a função teremos: $\ln Y_{t}=\beta_{1}+\beta_{2} t$, inserindo o termo de erro, temos que $\ln Y_{t}=\beta_{1}+\beta_{2} t+u_{i}$ sendo "t'" o número correspondente do período, variando de $1,2,3$...n. e se comportando da mesma forma que $\mathrm{X}$, logo existe regressão para $\mathrm{Y}$ e é possível calcular-se a taxa de crescimento geométrica e composta.

Para os cálculos das taxas de crescimento geométricas e compostas, são utilizados dados secundários da FAO, do MDIC/SECEX e do IBGE, com o auxílio do software Excel 2003, Excel 2007 e Gretl.

\section{Modelo "Constant-Market-Share" (CMS)}

Conforme abordagens de Leamer e Stern (1970), mais recente Carvalho (1995), Stalder (1997), a forma mais simples do modelo CMS, é definida como:

$\mathrm{S}=\mathrm{q} / \mathrm{Q}=\mathrm{f}^{\prime}(\mathrm{c} / \mathrm{C}), \mathrm{f}^{\prime}>0$

onde:

$\mathrm{S}=$ participação das exportações do país no comércio internacional;

q e $\mathrm{Q}=$ quantidades exportadas do país e do mundo, respectivamente;

c e $\mathrm{C}=$ competitividade do país e do mundo, respectivamente.

Quando se consideram a pauta e os diferentes mercados de destino, a variação no quantum exportado pode se dever não apenas à evolução do comércio ou da competitividade relativa, mas também da estrutura de exportações. Assim, se a pauta do país é formada preponderantemente de produtos cuja demanda mundial é crescente e/ou a economia de seus principais parceiros comerciais está em crescimento, fatalmente suas exportações aumentam, independentemente do que ocorre com a competitividade relativa. Dessa forma, considerando a expressão (1), temos:

$\mathrm{S}_{\mathrm{ij}}=\mathrm{q}_{\mathrm{ij}} / \mathrm{Q}_{\mathrm{ij}}=\mathrm{f}_{\mathrm{ij}}\left(\mathrm{c}_{\mathrm{ij}} / \mathrm{C}_{\mathrm{ij}}\right), \mathrm{f}_{\mathrm{ij}}>0$,

em que: $\mathrm{i}=$ produto $\mathrm{j}$ = países de destino.

Quando esta metodologia é aplicada a uma base empírica, é necessário pensar em variações discretas no tempo, e não mais em termos de mudanças infinitesimais, possíveis quando se opera com funções contínuas. Além disso, a necessidade de agregar mercadorias heterogêneas impõe que se opere com os valores das exportações, e não quantidades. Por esta razão, o modelo mais simples, que não distingue produtos e mercados, fica:

$\mathrm{V}^{*} . .-\mathrm{V} . .=\mathrm{rV} . .+\left(\mathrm{V}^{*} . .-\mathrm{V} . .-\mathrm{rV} ..\right)$

(a) (b)

em que:

V.. = valor total das exportações no período 1 (inicial)

$\mathrm{V}^{*}$. . = valor total das exportações no período 2 (final)

$\mathrm{r}=$ incremento das exportações mundiais do período 1 para o período 2

A variação das exportações do país de um período a outro está associada à variação das exportações mundiais (a) e a um efeito residual atribuído à competitividade (b). Comoas exportações compõemse de um conjunto diverso de produtos, tem-se para o i-ésimo produto uma expressão análoga à (2):

$$
\mathrm{V}^{*}{ }_{\mathrm{i} \cdot}-\mathrm{V}_{\mathrm{i}^{\cdot}}=\mathrm{r}_{\mathrm{i}} \mathrm{V}_{\mathrm{i}^{\cdot}}+\left(\mathrm{V}^{*}{ }_{\mathrm{i}} \cdot-\mathrm{V}_{\mathrm{i}}-\mathrm{r}_{\mathrm{i}} \mathrm{V}_{\mathrm{i} \cdot}\right)
$$

onde:

$\mathrm{V}_{\mathrm{i}} . .=$ valor total das exportações do produto i no período 1; 
$\mathrm{V}^{*}{ }_{\mathrm{i}}=$ valor total das exportações do produto i no período 2;

$\mathrm{r}_{\mathrm{i}}=$ incremento das exportações mundiais do produto i do período1 para o período 2

Esta expressão pode ser agrupada em:

$$
\begin{aligned}
& \mathrm{V}^{*} . .-\mathrm{V}_{. .}=\sum \mathrm{r}_{\mathrm{i}} \mathrm{V}_{\mathrm{i}^{*}}+\sum\left(\mathrm{V}^{*}{ }_{\mathrm{i}} \cdot-\mathrm{V}_{\mathrm{i}}-\mathrm{r}_{\mathrm{i}} \mathrm{V}_{\mathrm{i}}\right) \\
& \mathrm{V}^{*} . .-\mathrm{V}_{. .}=\left(\mathrm{r} \mathrm{V}_{. .}\right)+\sum\left(\mathrm{r}_{\mathrm{i}}-\mathrm{r}\right) \mathrm{V}_{\mathrm{i}} \cdot+\sum\left(\mathrm{V}^{*}{ }_{\mathrm{i}} \cdot \mathrm{V}_{\mathrm{i}}-\mathrm{r}_{\mathrm{i}} \mathrm{V}_{\mathrm{i}} \cdot\right)
\end{aligned}
$$

Finalmente, considerando a diferenciação das exportações por mercados de destino, chega-se à equação de CMS para o tipo particular de produto e uma região particular de destino:

$\mathrm{V}^{*}{ }_{\mathrm{ij}}-\mathrm{V}_{\mathrm{ij}}=\mathrm{r}_{\mathrm{ij}} \mathrm{V}_{\mathrm{ij}}+\left(\mathrm{V}_{\mathrm{ij}}^{*}-\mathrm{V}_{\mathrm{ij}}-\mathrm{r}_{\mathrm{ij}} \mathrm{V}_{\mathrm{ij}}\right)$ em que:

$\mathrm{V}_{\mathrm{ij}}=$ valor total das exportações do produto i para o país j no período 1 ;

$\mathrm{V}^{*}{ }_{\mathrm{ij}}=$ valor total das exportações do produto i para o país j no período 2 ;

$\mathrm{r}_{\mathrm{ij}}=$ incremento das exportações mundiais do produto i para o país j do período 1 para o período 2 .

Da mesma forma, esta equação pode ser agrupada em:

$$
\begin{aligned}
& \mathrm{V}_{\mathrm{ijji}}{ }^{*} . .-\mathrm{V}_{. .}=\sum \sum \mathrm{r}_{\mathrm{ij}} \mathrm{V}_{\mathrm{ij}}+\sum \sum\left(\mathrm{V}^{*}{ }_{\mathrm{ij}}-\mathrm{V}_{\mathrm{ij}}-\mathrm{r}_{\mathrm{ij}} \mathrm{V}_{\mathrm{ij}}\right) \\
& \mathrm{V}_{\mathrm{ijji}}{ }^{*} . .-\mathrm{V}_{.}=\mathrm{rV} . .+\sum\left(\mathrm{r}_{\mathrm{i}}-\mathrm{r}\right) \mathrm{V}_{\mathrm{i} .}+\sum \sum\left(\mathrm{r}_{\mathrm{ij}}-\mathrm{r}_{\mathrm{i}}\right) \mathrm{V}_{\mathrm{ij}}+\sum \sum\left(\mathrm{V}_{\mathrm{ij}}-\mathrm{V}_{\mathrm{ij}}-\mathrm{r}_{\mathrm{ij}} \mathrm{V}_{\mathrm{ij}}\right)
\end{aligned}
$$
(a)
(b)
(c)
(d)

E os efeitos (a) e (b) são relacionados a fatores externos, e os efeitos (c) e (d), a fatores internos:

a. efeito crescimento do comércio mundial; incremento observado se as exportações tiverem crescidoà mesma taxa decrescimento do comércio mundial;

b. efeito composição da pauta de exportação; mudanças na estrutura da pauta com concentração em produto com crescimento de demanda mais ou menos acelerado;

c. efeito destino das exportações; mudanças decorrentes de exportações de produtos para mercados de crescimento mais ou menos dinâmicos; e d. efeito residual, representando a competitividade; que reflete a diferença entre o crescimento atual e o crescimento que teria ocorrido nas exportações, se sua parcela de exportações de cada bem para cada país tivesse sido mantida.

$\mathrm{O}$ efeito pauta de exportações (b), $\Sigma\left(\mathrm{r}_{\mathrm{i}}-\mathrm{r}\right) \mathrm{V}_{\mathrm{i}}$. indica que se as exportações mundiais do produto $\mathrm{i}$ aumentaram mais que a média mundial para todas as mercadorias exportadas: $\left(\mathrm{r}_{\mathrm{i}}-\mathrm{r}\right)$ é positivo, e tornará forte esse efeito se $\mathrm{V}_{\mathrm{i}}$. for relativamente grande, ou seja, o efeito composição da pauta será positivo se as exportações estiverem concentradas no produto de maior expansão ou quando a taxa de crescimento for superior à média mundial.

$\mathrm{O}$ efeito destino das exportações (c), $\Sigma \Sigma\left(\mathrm{r}_{\mathrm{ij}}-\mathrm{r}_{\mathrm{i}}\right)$ $\mathrm{V}_{\mathrm{ij}}$, será positivo se o país tiver concentrado suas exportações em mercados que experimentaram maior dinamismo no período analisado, e negativo se concentrado em regiões mais estagnadas.

$\mathrm{O}$ efeito competitividade (d) significa que uma economia é competitiva na produção de determinada mercadoria quando consegue, pelo menos, igualarse aos padrões de eficiência vigente no resto do mundo quanto à utilização de recursos e à qualidade do bem.

A diferença entre o crescimento das exportações verificadas pelo modelo CMS e o crescimento efetivo das exportações é atribuída ao efeito competitividade. A medida deste efeito está relacionada com mudanças nos preços relativos. Assim, quando um país deixa de manter sua parcela no mercado mundial, o termo competitividade torna-se negativo e os preços crescem para o país frente aos preços de seus competidores.

\section{Resultados e discussão}

A análise das taxas de crescimento das exportações de frangos revela a existência de uma diferença entre os valores da variação percentual e da 
taxa de crescimento composta no período, conforme justificado na metodologia (Ver Tabela 5).

O Brasil teve uma taxa de crescimento composta no período de $591,02 \%$ eo crescimento mundial foi de $145,16 \%$ no período. Dos principais países, a Argentina teve o maior crescimento com uma taxa composta de $11.884,22 \%$ no período. A França teve uma elevação nas exportações comparada ao valor de 1990; entretanto, seu crescimento ao longo do período foi negativo, traduzindo as oscilações nas exportações. Também se deve considerar que a Polônia, China e Hong Kong tinham um valor $-\mathrm{p}$ não significativo a $5 \%$ de significância. $\mathrm{O}$ valor da Polônia acabou traduzindo os valores nulos de alguns anos da série, justificando um coeficiente nãosignificativo. Para os outros valores, as oscilações ao longo do período traduziram em variâncias elevadas, conseqüentemente o MQO não irá captar essas oscilações incorrendo em erro. Entretanto, se os valores forem comparados às variações percentuais, vê-se que não existe uma diferença significativa, e pode aceitar-se os dados com estas ressalvas.

O crescimento das exportações de carnes de aves também ilustra a tentativa de substituição do consumo pela carne bovina que, na última década, sofreu graças às doenças bovinas que tinham ligação com doenças humanas, ou seja, a demanda de uma forma geral caiu nos países que tinham seus rebanhos nas áreas de risco.

Em relação às importações mundiais, a Tabela 6 ilustra os principais países importadores, com posição relativa aos dados de 2005 .

Tabela 5. Variação e taxas de crescimentos dos principais exportadores e do total mundial de carne de frangos no período de 1990 a 2005.

\begin{tabular}{|c|c|c|c|c|c|c|}
\hline $\begin{array}{l}\text { Países de } \\
\text { Destino }\end{array}$ & $\begin{array}{l}\text { Variação } \\
\%\end{array}$ & $\begin{array}{l}\text { Taxa Crescimento } \\
\text { Instantâneo \% }\end{array}$ & $\begin{array}{c}\text { Taxa de } \\
\text { Crescimento } \\
\text { Composta } \\
\%\end{array}$ & $\begin{array}{c}\text { Taxa Crescimento } \\
\text { Composta } \\
\text { Período } \\
\% \\
\end{array}$ & Erro Padrão & $\begin{array}{c}\text { Estatística } \\
t\end{array}$ \\
\hline Mundo & 279,0 & 5,60 & 5,76 & 145,16 & 0,0158993 & 3,525 \\
\hline Brasil & 990,5 & 12,08 & 12,84 & 591,02 & 0,0174963 & 6,905 \\
\hline $\begin{array}{l}\text { Estados } \\
\text { Unidos }\end{array}$ & 308,3 & 6,06 & 6,24 & 163,55 & 0,0226444 & 2,675 \\
\hline Holanda & 123,0 & 2,21 & 2,23 & 42,40 & 0,0143984 & 1,534 \\
\hline Franca & 34,0 & $-0,93$ & $-0,92$ & $-13,77$ & 0,0152464 & $-0,607$ \\
\hline Alemanha* & 817,1 & 11,00 & 11,63 & 481,28 & 0,0196925 & 5,586 \\
\hline Reino Unido & 621,4 & 9,22 & 9,66 & 337,45 & 0,020872 & 4,419 \\
\hline Polônia** & 348,4 & 8,29 & 8,65 & 276,92 & 0,0687455 & 1,206 \\
\hline China & 128,0 & 3,51 & 3,57 & 75,39 & 0,0411626 & 0,853 \\
\hline Hong Kong & 133,7 & 5,97 & 6,15 & 159,99 & 0,0392711 & 1,521 \\
\hline Itália & 619,2 & 11,34 & 12,00 & 513,37 & 0,0182187 & 6,222 \\
\hline Argentina & 6796,2 & 29,91 & 34,87 & $11.884,22$ & 0,0363887 & 8,221 \\
\hline
\end{tabular}

Fonte: Dados da FAO, 2007, online. Elaboração dos autores.

*Para o cálculo da variação percentual, foi utilizado como valor inicial o ano de 1991.

**Para o cálculo da variação percentual, foi utilizado como valor inicial o ano de 1992. 
Tabela 6. Evolução das importações dos principais países e do total mundial de carne de frangos no período de 1990 a 2005 (em 1.000 US\$).

\begin{tabular}{lrrrrrrrr}
\hline $\begin{array}{l}\text { Países de } \\
\text { Destino }\end{array}$ & $1990 / 1991$ & $1992 / 1993$ & $1994 / 1995$ & $1996 / 1997$ & $1998 / 1999$ & $2000 / 2001$ & $2002 / 2003$ & $2004 / 2005$ \\
\hline Mundo & 4.857 .630 & 5.732 .444 & 9.588 .262 & 10.295 .392 & 10.143 .652 & 8.235 .720 & 10.932 .338 & 15.916 .295 \\
Reino Unido & 543.981 & 639.640 & 913.856 & 1.058 .636 & 1.411 .677 & 1.009 .328 & 1.334 .929 & 2.347 .563 \\
Japão & 1.184 .092 & 1.291 .298 & 2.521 .691 & 2.449 .446 & 1.736 .379 & 1.157 .701 & 1.286 .097 & 1.505 .628 \\
Rússia* & 0 & 0 & 0 & 0 & 402.707 & 662.127 & 1.075 .724 & 1.352 .018 \\
Arábia Saudita* & 0 & 0 & 0 & 0 & 325.747 & 433.097 & 556.980 & 1.025 .065 \\
Alemanha** & 541.177 & 1.060 .604 & 1.360 .291 & 1.431 .525 & 977.895 & 601.947 & 793.043 & 1.111 .033 \\
Hong Kong & 319.527 & 509.670 & 1.332 .577 & 1.663 .208 & 1.353 .673 & 938.392 & 844.584 & 899.516 \\
Holanda & 160.494 & 225.362 & 396.347 & 484.493 & 378.189 & 223.220 & 452.858 & 755.766 \\
França & 132.172 & 166.346 & 360.156 & 444.416 & 381.590 & 291.337 & 401.342 & 717.406 \\
China & 92.545 & 90.028 & 167.695 & 295.678 & 470.155 & 602.614 & 637.257 & 473.129 \\
México & 78.216 & 117.152 & 203.003 & 117.782 & 174.216 & 165.332 & 225.185 & 433.976 \\
Brasil*** & 527 & 58 & 1.066 & 3.414 & 1.926 & 457 & 830 & 978 \\
\hline
\end{tabular}

Fonte: Dados da FAO, 2007, online. Elaboração dos autores.

* Para o cálculo da variação percentual, foi utilizado como valor inicial o ano de 1998.

**Para o cálculo da variação percentual, foi utilizado como valor inicial o ano de 1991.

*** Apenas para comparação.

O Brasil importa relativamente pouco do complexo de carne de frangos, uma vez que possui uma estrutura produtiva que permite que a demanda interna seja atendida pelos produtores internos. O Reino Unido, seguido do Japão e da Rússia, representam 33\% da demanda mundial.

Analisando as taxa de crescimento, vemos que os países que tiveram maior crescimento foram à Rússia, seguido da China. O Brasil foi colocado apenas para comparação uma vez que a totalidade de sua demanda é quase atendida internamente (Ver Tabela 7).

Algumas taxas apresentaram valores de coeficientespoucosignificativos, dadaavariabilidade existente na série e que o MQO não captou, além do que, a Rússia e a Arábia Saudita só possuíam valores positivos nas importações a partir de 1998, o que compromete o cálculo econométrico.

A Tabela 8 mostra que, entre os principais rebanhos, o de galos, frangos e pintos cresceu a uma taxa elevada, de 5,19\% ao ano, próxima da taxa de crescimento geométrica sem regressão. O acumulado do período para o crescimento do rebanho foi de $113,61 \%$, ressaltando um maior envolvimento da produção voltado para esse tipo de carne. O crescimento das exportações, motivado pela alocação da produção nos países livre da gripe aviária, ainda não foi captado de forma clara, uma vez que o último período de análise foi 2005. 
Tabela 7. Variação e taxas de crescimentos dos principais importadores e do total mundial de carne de frangos no período de 1990 a 2005.

\begin{tabular}{lcccccc}
\hline Países de Destino & $\begin{array}{c}\text { Variação } \\
\text { Percentual }\end{array}$ & $\begin{array}{c}\text { Taxa } \\
\text { Crescimento } \\
\text { Instantâneo \% }\end{array}$ & $\begin{array}{c}\text { Taxa de } \\
\text { Crescimento } \\
\text { Composta }\end{array}$ & $\begin{array}{c}\text { Taxa } \\
\text { Crescimento } \\
\text { Composta } \\
\text { Período }\end{array}$ & Erro Padrão & Estatística $t$ \\
\hline Mundo & 275,5 & 6,53 & 6,74 & 184,14 & 0,0114796 & 5,686 \\
Reino Unido & 338,4 & 8,49 & 8,86 & 289,16 & 0,0119761 & 7,091 \\
Japão & 59,3 & $-0,55$ & $-0,55$ & $-8,48$ & 0,0178006 & $-0,311$ \\
Rússia* & 110,7 & 30,82 & 36,10 & $13.761,44$ & 0,168778 & 1,826 \\
Arábia Saudita* & 96,4 & 10,20 & 10,74 & 411,79 & 0,0618652 & 1,649 \\
Alemanha** & 14,0 & $-2,79$ & $-2,76$ & $-36,05$ & 0,0170716 & $-1,637$ \\
Hong Kong & 171,8 & 5,17 & 5,30 & 128,59 & 0,0271976 & 1,9 \\
Holanda & 410,6 & 7,12 & 7,38 & 212,63 & 0,0216108 & 3,297 \\
França & 484,2 & 9,09 & 9,52 & 328,40 & 0,0176536 & 5,151 \\
China & 640,0 & 14,82 & 15,97 & 970,37 & 0,0229688 & 6,451 \\
México & 661,9 & 8,63 & 9,01 & 297,84 & 0,0166749 & 5,176 \\
Brasil*** & 58,3 & 13,05 & 13,94 & 707,46 & 0,0915006 & 1,427 \\
\hline
\end{tabular}

Fonte: Dados da FAO, 2007, online. Elaboração dos autores.

*Para o cálculo da variação percentual, foi utilizado como valor inicial o ano de 1998.

**Para o cálculo da variação percentual, foi utilizado como valor inicial o ano de 1991.

*** Apenas para comparação.

Tabela 8. Variação e taxas de crescimentos dos principais rebanhos brasileiros no período 1990-2005. (em \%).

\begin{tabular}{lrrrrr}
\hline Rebanho & Variação & $\begin{array}{c}\text { Taxa de } \\
\text { crescimento } \\
\text { geométrica }- \\
\text { sem regressão }\end{array}$ & $\begin{array}{c}\text { Taxa de } \\
\text { crescimento } \\
\text { geométrica } \\
\text { instantânea }\end{array}$ & $\begin{array}{c}\text { Taxa de } \\
\text { crescimento } \\
\text { geométrica } \\
\text { composta }\end{array}$ & $\begin{array}{c}\text { Taxa de } \\
\text { crescimento } \\
\text { geométrica } \\
\text { composta no } \\
\text { período }\end{array}$ \\
\hline Bovinos** & 40,8 & 2,31 & 2,11 & 2,13 & 37,23 \\
Galos, Frangos e pintos** & 118,6 & 5,35 & 5,06 & 5,19 & 113,61 \\
Suínos* & 1,31 & 0,09 & $-0,38$ & $-0,38$ & $-5,59$ \\
Eqüinos* & $-5,5$ & $-0,37$ & $-0,64$ & $-0,64$ & $-9,15$ \\
\hline
\end{tabular}

Fonte: Elaborado pelo autor a partir de dados do IBGE (2007).

* Valores não significativos $\operatorname{com} \alpha=5 \%$.

$* *$ Valores significativos com $\alpha=5 \%$.

$\mathrm{O}$ modelo CMS, aplicado às exportações brasileiras, permitiu analisar os efeitos relacionados ao crescimento do comércio mundial, composição da pauta de exportações, destino das exportações e sua competitividade nos três subperíodos considerados.
A Tabela 9 mostra a decomposição das fontes de crescimento das exportações brasileiras de carnes e suas taxas de crescimento em comparação às mundiais. Para isso, a série foi dividida em três períodos. Também é possível analisar o marketshare - participação de mercado em cada período analisado. 
Tabela 9. Taxas e fontes de crescimento das exportações brasileiras de carne de aves, em \% - 1990 a 2005.

\begin{tabular}{|c|c|c|c|}
\hline \multirow{3}{*}{ Indicadores } & \multicolumn{3}{|c|}{ Períodos } \\
\hline & 1990 a 94 & 1995 a 99 & 1990 a 94 \\
\hline & 1995 a 99 & 2000 a 05 & 2000 a 05 \\
\hline \multicolumn{4}{|l|}{ a) Taxas de crescimento } \\
\hline Exportações mundiais & 93,1 & $(7,4)$ & 44,1 \\
\hline Exportações brasileiras & 90,3 & 91,3 & 72,5 \\
\hline Market-Share & 12,8 & 19,3 & 18,0 \\
\hline \multicolumn{4}{|l|}{ b) Fontes de crescimento } \\
\hline Crescimento do comércio mundial & 48,9 & $(3,9)$ & 287,1 \\
\hline Destino das exportações & $(10,9)$ & 11,0 & 62,7 \\
\hline Competitividade & 62,0 & 92,8 & $(249,9)$ \\
\hline
\end{tabular}

Fonte: Elaborado pelos autores, 2007

A análise dos resultados do complexo de aves, apresentados na Tabela 9, revela que o Brasil acompanhou o crescimento das exportações mundiais, o market-share é elevado, representando em média 19,3\% no período 1995-2005. As taxas de crescimento traduzem os outros resultados encontrados, ou seja, houve crescimento nas exportações brasileiras acima da taxa mundial.

Em relação às fontes de crescimento, grande parte se deve ao crescimento do comércio mundial e da competitividade. Da mesma forma que o sistema bovino, o de aves tem elevado potencial para ampliar o melhorar o item destino das exportações, pois as mesmas estão concentradas em alguns mercados selecionados.

No que tange à pauta de exportações, o valor nulo traduz a utilização de um tipo de carne, ou seja, dentro do complexo carne o de aves é um segmento específico, logo não há diferenciação que permita análise de ganhos de diversificação.
Os dados de destino de exportação mostram que o Brasil aumentou a exportação de seus produtos para os países que mais elevaram suas importações, ou seja, o destino foi os maiores importadores.

A competitividade brasileira vem se elevando, prova que no período 1995-2005 o valor das exportações aumentou 92,8\%. Já o valor negativo traduz o efeito residual para períodos distintos. Internamente, o maior exportador/produtor de aves é o Estado do Paraná e, por meio dos mesmos métodos, pode-se calcular sua competitividade e evolução.

A Tabela 10 ilustra as variações e as taxas calculadas por MQO, para as carnes paranaenses. Vê-se que o complexo frango de corte foi o que mais cresceu, e os complexos bovinos e suínos apresentaram taxas positivas para o período. Em relação ao rebanho de galinhas e eqüinos, os dados apresentaram uma oscilação maior, que se traduziu em erro padrão maior, incorrendo em coeficientes não significativos. 
Tabela 10. Variação e taxas de crescimentos dos principais rebanhos paranaenses no período de 1990 a 2005.

\begin{tabular}{lcccccc}
\hline $\begin{array}{l}\text { Países de } \\
\text { Destino }\end{array}$ & $\begin{array}{c}\text { Variação } \\
\text { Percentual }\end{array}$ & $\begin{array}{c}\text { Taxa } \\
\text { Crescimento } \\
\text { Instantâneo \% }\end{array}$ & $\begin{array}{c}\text { Taxa de } \\
\text { Crescimento } \\
\text { Composta }\end{array}$ & $\begin{array}{c}\text { Taxa } \\
\text { Crescimento } \\
\text { Composta } \\
\text { Período }\end{array}$ & Erro Padrão & Estatística $t$ \\
\hline Bovinos & 17,8 & 1,32 & 1,33 & 23,59 & 0,0016108 & 8,219 \\
Suínos & 27,7 & 1,59 & 1,60 & 28,95 & 0,0009121 & 17,419 \\
Galinhas & $-2,2$ & $-0,53$ & $-0,53$ & $-8,16$ & 0,0037932 & $-1,403$ \\
Galos, & 188,1 & 7,22 & 7,49 & 217,63 & 0,004119 & 17,536 \\
$\begin{array}{l}\text { Frangos e } \\
\text { pintos }\end{array}$ & $-5,0$ & 0,13 & 0,13 & 2,12 & 0,0025324 & 0,518 \\
Eqüinos & $-2,0$ & & & \\
\hline
\end{tabular}

Fonte: Dados IBGE, 2007, online. Elaboração dos autores.

Ao aplicar o modelo CMS para o Estado do Paraná, pode-se verificar como este se comportou no período de análise.

ATabela 11 mostra que houve um crescimento das exportações paranaenses superiores às mundiais, e o complexo foi atuante ao longo do período. Os dados de market-share evidenciam que a participação do estado no mercado mundial é elevada e em toda a série este foi positivo. As fontes de crescimento decompostas mostram que, nos períodos um e três, o Paraná acompanhou o crescimento mundial. A composição da pauta traduz novamente a não diferenciação uma vez que estamos trabalhando com apenas um produto. O componente destino das exportações traduz a elevação das exportações para os maiores países importadores, ou seja, os não estagnados.

O resíduo positivo pode ser interpretado como ganhos de competitividade para o período; entre 1995-2005 os ganhos foram de $25,3 \%$.

Tabela 11. Taxas e fontes de crescimento das exportações paranaenses de carne de aves, em \% - 1990 a 2005.

\begin{tabular}{|c|c|c|c|}
\hline \multirow{3}{*}{ Indicadores } & \multicolumn{3}{|c|}{ Períodos } \\
\hline & 1990 a 94 & 1995 a 99 & 1990 a 94 \\
\hline & 1995 a 99 & 2000 a 05 & 2000 a 05 \\
\hline \multicolumn{4}{|l|}{ a) Taxas de crescimento } \\
\hline Exportações mundiais & 93,1 & $(7,4)$ & 44,1 \\
\hline Exportações paranaenses & 92,9 & 116,1 & 76,0 \\
\hline Market-Share & 3,0 & 5,0 & 4,6 \\
\hline \multicolumn{4}{|l|}{ b) Fontes de crescimento } \\
\hline Crescimento do comércio mundial & 11,5 & $(0,9)$ & 77,4 \\
\hline Destino das exportações & $(2,6)$ & 2,6 & 16,9 \\
\hline Competitividade & 14,9 & 25,3 & $(70,8)$ \\
\hline
\end{tabular}

Fonte: Elaborado pelos autores, 2007. 
Os dados analisados mostram que o Brasil e o Estado do Paraná possuem elevada competitividade no complexo avícola. Entretanto, a existência de medidas protecionistas pode atrapalhar a evolução do complexo. Segundo Martinelli e Souza (2005, p.1), as políticas protecionistas utilizadas pelos países importadores de aves brasileiras agrupam-se em três grupos mais comuns:

- barreiras tarifárias (tarifas de importação, novas taxas e valoração aduaneira);
- barreiras não-tarifárias (Imposição de quotas, restrições quantitativas, licenciamento de importações, procedimentos alfandegários, medidas antidumping e compensatórias);

- barreiras técnicas (normas e regulamentos técnicos, regulamentos sanitários, fitossanitários e de saúde animal).

O Quadro1 identifica as principais barreiras existentes para dada as principais localidades existentes.

\begin{tabular}{|c|c|c|}
\hline Localidade & Barreira & Observação \\
\hline Estados Unidos & Subsídios & $\begin{array}{l}\text { O preço médio das exportações americanas, US\$ } 700 \text { / ton, é muito inferior } \\
\text { aos preços internacionais médios (nunca abaixo de US\$1.000 / ton). O quilo } \\
\text { do frango cobrado do consumidor norte-americano (superior a US\$2,00) é } \\
\text { quase o dobro do que é praticado no mercado brasileiro (R } \$ 2,00) \text {, mostrando } \\
\text { a competitividade do país nesse setor. } \\
\text { O comércio de aves com os EUA é também prejudicado pela falta de acordo } \\
\text { sanitário entre as partes, que também se justifica pelo receio do Ministério } \\
\text { da Agricultura de que o mercado brasileiro seja invadido pelas carnes de } \\
\text { frango norte-americanas, principalmente pedaços não consumidos naquele } \\
\text { mercado. }\end{array}$ \\
\hline União Européia & $\begin{array}{l}\text { Tarifas altas; } \\
\text { Quotas tarifárias; } \\
\text { Subsídios } \\
\text { Ajuda interna } \\
\text { OCM* }\end{array}$ & $\begin{array}{l}\text { Tarifa: } 102.4 € / 100 \mathrm{~kg} / \mathrm{net} \text {, que corresponde a } 46,25 \% \text { ad valorem. } \\
\text { Quota de } 7.500 \mathrm{t} \text { para carne de aves, com tarifas } 50 \% \text { inferiores às normais } \\
-23,12 \% \text {. } \\
\text { Subsídio às exportações consolidado na OMC: } € 91,6 \text { Milhões em } 2000 \text {. } \\
\text { Valor destinado, como ajuda interna, a suínos, ovos e aves pela OCM em } \\
2000: € 236 \text { milhões. }\end{array}$ \\
\hline
\end{tabular}

Quadro 1. Principais barreiras existentes às exportações brasileiras de carne de aves

Fonte: Barreiras às exportações brasileiras (SERVIÇO DE COMÉRCIO EXTERIOR - SECEX, 2006) Trains / 2001 UNCTAD.

*OCM - Organizações Comuns de Mercado - políticas setoriais específicas financiadas pelo Fundo Europeu de Orientação e de Garantia Agrícola, mesmo fundo que financia a PAC - Política Agrícola Comum. 


\section{Conclusão}

O complexo da cadeia agroindustrial de carnes caracteriza-se pela existência de economias de escala e escopo, cuja exploração tem sido possível graças à existência de mecanismos em toda a cadeia que facilitam as ações conjuntas dos atores. Assim, ao examinar os aspectos da cadeia produtiva de carnes, verifica-se não apenas a competitividade do setor, mas também como todo o complexo de carnes onde este está engendrada e como evoui.

O sistema agroindustrial vem passando por transformações, sendo estas em grande parte a atender um novo padrão de demanda. Alimentos nutracêuticos surgem como opção para o salto da atual padrão de produção agroalimentar, a qual, em curto espaço de tempo, poderá desfrutar de tecnologias de medicamentos em alimentos.

A mudança no gosto do consumidor tem sido acompanhada pelo surgimento de um novo padrão organizacional na cadeia produtiva, e isso altera as relações entre os agentes em toda a cadeia, e engendra mudanças na produção, na distribuição. Estas estão associadas à inserção de multinacionais na cadeia produtiva, para que se altere a conformação dos elos entre os agentes e principalmente o poder de barganha que estes enfrentam, relevando a importância de uma gestão eficiente para o setor.

Apesar das transformações enfrentadas pelas cadeias agroindustriais, influenciadas pela inserção de novos produtos e processos, uma questão retorna a atenção quando se discute o ambiente macroeconômico. O novo padrão da agroindústria é derivado da adoção de novas tecnologias, mas também é fruto de um ambiente de incerteza macroeconômica que seleciona as empresas aptas a se manterem no mercado e estas continuarem a se desenvolver e se manter competitivas.

O estudo da competitividade da cadeia não deve se contentar com uma análise do entorno produtivo, mas também das relações a montante e a jusantes, sendo esta última de grande importância, uma vez que os consumidores ganham percepção de mercado crescente.

As análises das taxas de crescimento geométricas do complexo avícola permitiram aprofundar como este setor está desenvolvido e em condições de ser competitivas, dadas as condições ambientais internacionais que irão restringir as exportações de países afetados com a gripe aviária.

Ricardo e os teoremas subjacentes de comércio internacional acertaram ao analisar que países que possuíam vantagens comparativas ou fatores em excesso podiam ter competitividade ao se especializarem, porém o erro se encontra ao determinar a especialização em poucos bens. Ao longo dos períodos, há flutuações inerentes ao comércio internacional e a competitividade principalmente de commodities, e essa oscilação pode influenciar negativamente todo um setor agroexportador.

A análise dos dados permite concluir que o Brasil e o Estado do Paraná possuem competitividade no complexo de carne de aves, e podem vir atender a futuras oscilações na demanda do produto ligadas a outros países produtores. As taxas de crescimento revelam que o Brasil e o Paraná cresceram aceleradamente nos últimos dezesseis anos.

Dada a participação que ambos possuem no comércio mundial, este complexo tem importância nos planos internos (para gerar renda via exportação) e externo (para atender demandas futuras). Assim se recomenda que políticas voltadas ao setor sejam implementadas, tanto para elevar a capacidade de produção, melhorar as condições fitossanitárias que possam comprometer o complexo com as doenças avícolas, além da existência de um ambiente macroeconômico e comercial estável, uma vez que existem barreiras que encarecem o produto exportado ou mesmo taxas de câmbio desfavoráveis. A competitividade existente permite que ganhos adicionais possam ser adquiridos pelos produtores brasileiros e paranaenses, além de se tornar uma opção lucrativa aos outros complexos tradicionais. 
Futuros estudos que analisem a competitividade regional das exportações são recomendados, pois que cada região brasileira possui uma peculiaridade derivada das dimensões e particularidades territoriais.

\section{Referências}

CARVALHO, F.M.A. O comportamento das exportações brasileiras e a dinâmica do complexo agroindustrial. Tese (Doutorado em Economia). Escola Superior de Agronomia Luiz de Queiroz, Piracicaba, 1995.

CARVALHO, F. M. A. de. O comportamento das exportações brasileiras e a dinâmica do complexo agroindustrial. Piracicaba, 1995. 126p. Tese (Doutorado) - Escola Superior de Agricultura "Luiz de Queiroz"/ Universidade de São Paulo, 1995.

CARVALHO, T. B. ; BACCHI, Mirian Rumenos Piedade . Estudo da Elasticidade-renda da demanda de carne bovina, suína e de frango no Brasil. In: XLV Congresso da Sociedade Brasileira de Economia, Administração e Sociologia Rural, 2007, Londrina. Conhecimentos para a Agricultura do Futuro, 2007.

CARVALHO, M. A.; SILVA, C. R. L. Economia internacional. São Paulo: Saraiva, 2004.

COUTINHO, L.; FERRAZ, J. C. Estudo $d a$ competitividade da indústria brasileira. Campinas: Papirus, 1994.

DANTAS, A.; KERTNETZKY, J.; PROCHNIK, V. Empresa, indústria e mercados. In: KUPFER, D.; HASENCLER, L. (Org). Economia Industrial: fundamentos teóricos e práticos no Brasil. Rio de Janeiro: Elsevier, 2002.

FERRAZ, J. C.; KUPFER, D.; HAGUENAUER, L. Made in Brazil: desafios competitivos para a indústria. Rio de janeiro: Campus, 1995.

FAO. FAOSTAT - Banco de dados. Disponível em: $<$ http://apps.fao.org/faostat/form?collection=Trade LiveAnimal\&Domain $=$ Trade $\&$ servlet $=1 \&$ hasbulk $=$ $0 \&$ version $=$ ext\&language $=\mathrm{EM}>$. Acesso em 03 de março de 2007.

GUJARATI, D. Econometria básica. Rio de Janeiro: Elsevier, 2006.
KRUGMAN, P.; OBSTFELD, M. Economia internacional: teoria e política. São Paulo: Makron, 2004.

LEAMER, E. E.; STERN, R. M. Constant-market-share analysis of export growth. In: Quantitative international economics. Boston: Allyn and Bacon, 1970. p. 171-183.

MARAFON, G. J. ; MADANELO, Daniela Helena V de Lima . O complexo agroindustrial da pecuária de leite no estado do Rio de Janeiro. In: XLII Congresso da Sociedade Brasileira de Economia e Sociologia Rural, 2004, Cuibá-MT. Anais do XLII Congresso da Sociedade Brasileira de Economia e Sociologia Rural, 2004.

MARAFON,G.J.Industrializaçãodaagriculturaeformação do Complexo Agroindustrial no Brasil. Disponível em: $<$ www.educacaopublica.rj.gov.br/biblioteca/geografia/ geo06d.htm>. Acesso em: 4 de setembro de 2007.

MARTINELLI, O.; SOUZA, J. M. Relatório setorial final: carne de aves. 2005. Disponível em: $<\mathrm{http}: / /$ www.finep.gov.br/PortalDPP/relatorio_setorial_final/ relatorio_setorial_final_impressao.asp? ${ }_{1}$ st_setor $=25>$. Acesso em: 8 jul. 2006.

MINISTÉRIO DO DESENVOLVIMENTO INDUSTRIAL E COMÉRCIO EXTERIOR - MDIC. Banco de dados do sistema Aliceweb. Disponível em: $<$ http://aliceweb.desenvolvimento.gov.br/default.asp>. Acesso em: 25 mar. 2007.

RIZZI, A. T. A indústria de frangos no Brasil: constituição e transformações. módulo de economia industrial. In: ENCONTRO DE HISTÓRIA ECONÔMICA, 3., 1999, Curitiba. Anais... Curitiba: ABPHE, 1999. (CD-ROM).

SERVIÇO DE COMÉRCIO EXTERIOR - SECEX. Barreiras às exportações brasileiras. Disponível em: $<$ http://www.desenvolvimento.gov.br/sitio/secex/ negInternacionais/barExtInfComerciais $>$. Acesso em: 10 ago. 2006.

STALDER, S. H. G. M. Análise da participação do Brasil no mercado internacional de açúcar. 1997. Dissertação (Mestrado em Economia) - Escola Superior de Agricultura Luiz de Queiroz, Piracicaba.

VEJA cronologia da gripe aviária desde seu surgimento em 2003. Folha Online. Disponível em: <http://www1. folha.uol.com.br/folha/mundo/ult94u93352.shtml>. Acesso em: 8 jul. 2006. 